\title{
Consistency of PPP GPS and strong-motion records: case study of Mw9.0 Tohoku-Oki 2011 earthquake
}

\author{
Panos Psimoulis ${ }^{1,2^{*}}$, Nicolas Houlié, ${ }^{2,3}$, Michael Meindl ${ }^{2}$, and Markus Rothacher ${ }^{2}$ \\ ${ }^{1}$ Nottingham Geospatial Institute, The University of Nottingham, Nottingham NG7 2TU, UK \\ ${ }^{2}$ Geodesy and Geodynamics Lab., Geodesy and Photogrammetry Institute, ETH Zurich, Zurich 8093, \\ Switzerland \\ ${ }^{3}$ Seismology and Geodynamics, Institute of Geophysics, ETH Zurich, Zurich 8092, Switzerland \\ (Received , Revised , Accepted )
}

\begin{abstract}
GPS and strong-motion sensors are broadly used for the monitoring of structural health and Earth surface motions, focusing on response of structures, earthquake characterization and rupture modeling. Several studies have shown the consistency of the two data sets within at certain frequency (e.g., $0.03<\mathrm{f}<0.2 \mathrm{~Hz}$ ). The compatibility of Precise Point Positioning (PPP) GPS and strong-motion data was assessed by comparing their respective displacement waveforms for several frequency bands $(\mathrm{f}<0.3 \mathrm{~Hz})$. For this purpose, there are used GPS and strong-motion records of the Mw9.0 Tohoku 2011 earthquake at 23 very close spaced sites and conclude that the agreement between the two datasets depends on the frequency of the excitation, the direction of the excitation signal and the distance from the excitation source.
\end{abstract}

Keywords: GPS, strong-motion, Tohoku earthquake, filter, time lag, displacement, coherence, frequency bands, consistency

\section{Introduction}

Structural health monitoring of structures at high-rate (i.e. up to $4 \mathrm{~Hz}$; Panagiotakos and Fardis, 1999) were supplemented by Global Navigation Satellite System (GNSS; Psimoulis et al., 2008; Psimoulis and Stiros, 2008; Penucci et al,. 2009; Sadan et al., 2013); itself recently improved by the introduction of high-rate GNSS measurement noise modeling (Moschas and Stiros, 2013), the more sophisticated processing algorithms (Psimoulis and Stiros, 2012; Wang and Rothacher, 2013) and the inclusion of the time-stamping of observations (Psimoulis and Stiros, 2013). In parallel the accurate monitoring estimation of the transient GPS antenna motion became important not

*Corresponding author, Lecturer in Geospatial Eng., E-mail:

Panagiotis.Psimoulis@nottingham.ac.uk 
only for the understanding of structures deformations, but also for the detection of tectonics motions (Chousianitis et al., 2013), and the characterization of deformation transients during or after the earthquake (Larson et al., 2003; Miyazaki et al., 2004; Blewitt et al., 2006; Feng et al., 2008; Ganas et al., 2009; Houlié et al., 2011; Yue and Lay, 2011; Wright et al., 2012; Houlié et al., 2014).

Until recently, the estimation of the displacement of the structure response and the corresponding excitation was based on accelerometers records (Wang et al., 2003, Feng, 2009). Such displacements time-series are, however affected by the seismic sensors saturation, significantly dominant for large excitation or large earthquakes (i.e. Sagiya et al., 2011) and characterized by systematic drift (Boore et al., 2003; Wang et al., 2003; Wang et al., 2007; Cauzzi and Clinton, 2013), which is increasing significantly with the duration of the acceleration record (Stiros, 2008). In the field of structure monitoring, high-rate GPS has been introduced as a complementary tool of accelerometers (Roberts et al., 2004; Chan et al., 2006; Meng et al., 2007; Chatzi and Fuggini, 2012; Moschas and Stiros, 2014; Yi et al., 2013) or Robotic Total Station (Moschas et al., 2013).

The developed Precise Point Positioning (PPP) processing mode of GNSS data, can produce displacement waveform of cm-accuracy level based on standalone GNSS station (Ge et al., 2008; Geng et al., 2011; Joakinen et al., 2013), improving the conditions of utilization of GNSS as realtime monitoring system. The quality of GPS time-series are continuously being improved and show potential (Crowell et al., 2009; Bock et al., 2011; Geng et al., 2013; Xu et al., 2013) for supplementing efficiently the earthquake early-warning systems (Kuyuk and Allen, 2014) and monitor remote structures (e.g. wind turbines; Giti and Lee, 2013). Still, the consistency of PPP GPS with strong-motion time-series have never been fully tested for oscillations in a wide range of frequencies (from $0.001 \mathrm{up}$ to $1 \mathrm{~Hz}$ ) such those generated by a seismic source. Indeed, because of its real-time capabilities, the accuracy of PPP displacement time-series might be decreased temporarily or even not sufficient to match the accuracy seismic sensors at long-periods. Such effort aims at i) assessing the displacement drift characteristic due to the double integration of acceleration records (Wang et al., 2003), ii) estimating the error propagation law explaining partly the accumulated error leading to the drift (Stiros, 2008), iii) quantifying the clipping of the strongmotion sensors (Clinton and Heaton, 2003) and finally iv) combining GPS and accelerograph to obtain single broadband displacement time series (Wang et al., 2007).

In this study, the data collected by three dense geophysical monitoring networks are used: the two strong motion networks of K-NET and KiK-net, and the GPS network of Japan during the Mw9.0 Tohoku-Oki 2011 earthquake. The latter is one the strongest and probably the bestrecorded megathrust earthquake (Wright et al., 2011), recorded in a broad area from the fault rupture (up to $75-800 \mathrm{~km}$ from the epicentre) by GPS and strong-motion network. Both of GPS and strong-motion sensors performed close to their limits due to the extreme ground motion, making this case representative for the assessment of their consistency and compatibility for sites in moderate and large distance $(>50 \mathrm{~km})$ from the subduction zone.

The study was focused on records of very closely spaced GPS and strong-motion sites. The distance of the examined close-spaced GPS and strong-motion data was varying and their consistency was evaluated, based on: i) their coherence analysis and ii) by comparing their displacement waveforms for several frequency bands. The study is focused on the correlation of the consistency of the GNSS and strong-motion data with the distance from the epicentre and the epicentre-site direction for their common frequency range. Main goal is to reveal potential consistency between the two sensors and how this could be beneficial for their supplementary use. 


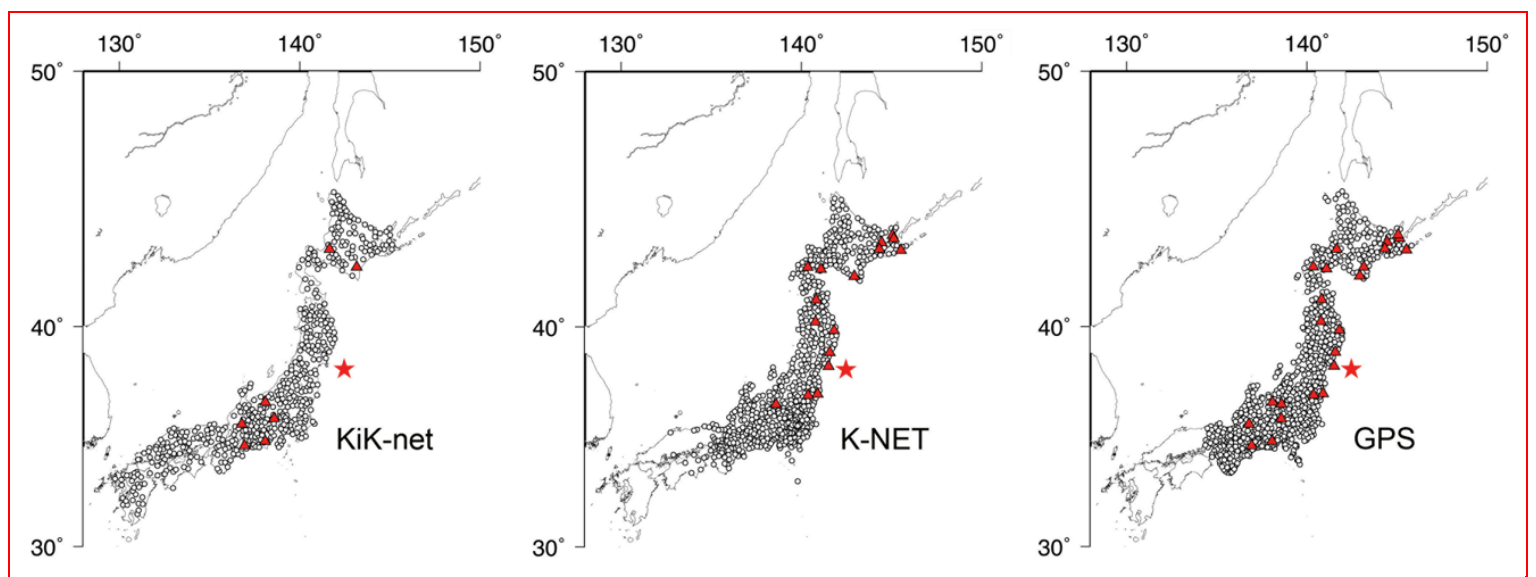

Fig. 1 The 23 very close spaced sites of the KiK-net/K-NET strong-motion networks with the GEONET GPS network (red triangles), as part of the available data of the three networks (white circles). The earthquake epicentre is marked as red star.

\section{Data}

\subsection{GPS data}

The Geospatial Information Authority of Japan (GSI) operates over 1200 continuously observing GPS receivers, known as GPS Earth Observation Network (GEONET), covering the Japanese land area with an average distance of about $20 \mathrm{~km}$ between neighboring points (Sagiya, 2004). The Mw9.0 earthquake off the Pacific coast of Tohoku on March 11, 2011 was well recorded by GEONET.

GPS records from 847 GEONET stations (Fig.1) of 15-hour duration (from 00:00:00 to 15:00:00 local time zone) and $1 \mathrm{~Hz}$ sampling rate were available. These data were covering adequately the period of the earthquake, whilst data of later period were limited. For the process of the GPS data was used the scientific Bernese GPS Software 5.0 (Dach et al., 2007). The data were post-processed in a Precise Point Positioning (PPP) mode using a-priori information (e.g. precise clock, precise orbit and erp information) of highest quality from the Center for Orbit Determination in Europe (CODE; Dach et al. 2009), for the GPS phase-only solution without though resolving the ambiguities. The PPP GPS process resulted in displacement time series in North, East, and vertical components (ITRF2008 reference frame) of $1 \mathrm{~Hz}$ sampling rate and of RMS approximately of $1 \mathrm{~cm}$ and $2 \mathrm{~cm}$ in horizontal and vertical component, which was consistent with the a-posteriori accuracy, derived from the noise ( $\pm 3 \sigma$ noise zone) of the resulted time series. Finally, for the sites examined in the current study consisted of antenna type TRM29659 and receiver Trimble 5700 or NETR9 or TPS NETG3.

\subsection{Strong motion data}


The strong-motion networks of Japan, K-NET (Kyoshin) and KiK-net (KIBAN Kyoshin) are composed of 1034 and 660 seismometers, respectively. The K-NET is deployed mostly on thick sedimentary ground, while the KiK-net is located on rock or thin sedimentary sites, as it is designed to capture high-accuracy seismic observation. Furthermore the triggering threshold of the KiK-net sensors is $0.2 \mathrm{~cm} / \mathrm{s}^{2}$, while that of K-NET sensors is $2 \mathrm{~cm} / \mathrm{s}^{2}$ (Aoi et al., 2004). K-NET is consisted of only surface stations, the KiK-net is consisted of two seismometers, installed at surface ground and at the bottom of boreholes of 100-200m depth. However, both the networks consist of the same instrumentation, using V403 or V404 tri-axial force balance accelerometer ( $450 \mathrm{~Hz}$ frequency and 0.707 damping factor).

The earthquake of Mw9.0 Tohoku 2011 was recorded successfully by the two strong-motion seismic networks and the raw data from $700 \mathrm{~K}-\mathrm{NET}$ sites and $525 \mathrm{KiK}$-net sites were available (Fig.1). The sampling rates of records is $100 \mathrm{~Hz}$ and their duration up to $300 \mathrm{sec}$. The acceleration of the each site derived by correcting the raw data from the gain and the corresponding record time, initially given in UTC time, was corrected (i.e. for 15 leap seconds) and transformed into GPS time.

\subsection{Very close spaced GPS - strong motion sites}

The evaluation of the consistency of the GPS and the strong-motion records is made using data collected by very close spaced sites of the GPS and strong-motion networks. At high frequency $(>1 \mathrm{~Hz})$, in order to complete a valid comparison, the seismic and geodetic sensors need to be as close as possible. Though, the two sensors are usually not perfectly collocated (less than $1 \mathrm{~m}$ ), as the seismic sensors are usually established indoor in order to ensure the good function and quality of the seismic data, while the GPS antennas need to be outdoor aiming to maximum possible visible GPS satellites in the sky. In the current study were used the sites, where the in between distance of the corresponding GPS and the strong-motion sensors was less than $100 \mathrm{~m}$, in order to limit the possibilities of getting influenced the recordings of the two sensors by local effects. Considering the minimum distance between the epicenter and the network ( $75 \mathrm{~km}$ for the GPS network), the distance between the two sensors (i.e. $<100 \mathrm{~m}$ ) and the GPS sampling rate (i.e. $1 \mathrm{sec}$ ), it was assumed that the same seismic motion was recorded by both GPS and strong-motion sensor without significant time difference between the two sensors records. Furthermore, the collocation limit of $100 \mathrm{~m}$ distance is within the limitations of previous studies for collocation between GPS and strong-motion sensors (Emore et al., 2007; Wang et al., 2013).

Amongst the three networks, 23 pairs of very close spaced sites of the GPS and strong-motion networks (16 K-NET and 7 KiK-net network; Table 1) were identified, without any malfunctions or delayed triggering (Fig. 1). In five of these 23 sites, the in between distance of the corresponding sensors was slightly above $100 \mathrm{~m}$ (up to $150 \mathrm{~m}$ ), in order to cover uniformly and broadly the range of $75-650 \mathrm{~km}$ of distance from the epicentre, for the three networks. Furthermore, regarding the very closed spaced sites of the seven examined KiK-net stations, only the records of the surface KiK-net sensors were used for the comparison with the corresponding GPS records in order to retain the consistency of the recording motion of the GPS and the strong-motion sensors. The records of the buried KiK-net record in the borehole was not included in the analysis due to: i) their larger distance from the corresponding GPS site relatively to that from the surface sensor and ii) potential small local effects, which would have larger impact on the recorded motion by the 
buried sensors relatively to that of the surface sensors, with respect always the motion recording by the GPS site. For simplicity from this point and on these 23 very close spaced sites will be referred as collocated sites from this point on.

\subsection{Definition of the GPS and strong-motion time series}

The acceleration time series of the strong-motion was defined according to the start and end time of the corresponding record, including the transformation from UTC to GPS time. The start time of the acceleration was 15 seconds before the arrival of the seismic signal at the corresponding site, as defined by the 15 -sec pre-triggering mode, and the end time was defined after 300sec duration period (Aoi et al., 2004). Thus, the derived acceleration time series of 300sec duration included the entire seismic motion of the event (i.e. body and surface waves). Regarding the GPS time series, they were defined according to the start and end time of the strongmotion record of the corresponding collocated site. The latter certified the common reference time and the compatibility of the time series of the GPS and strong-motion site.

Table 1: The collocated GPS and strong-motion sites of K-NET and KiK-net network with their location (latitude, longitude), distance from the epicentre, the distance between the two collocated sensors and the angle formed by each site, the epicentre and West

\begin{tabular}{cccccccc}
\hline GPS & K-NET & KiK-net & $\begin{array}{c}\text { Latitude } \\
(\mathrm{deg})\end{array}$ & $\begin{array}{c}\text { Longitude } \\
(\mathrm{deg})\end{array}$ & $\begin{array}{c}\text { Epicentre } \\
\text { distance } \\
(\mathrm{km})\end{array}$ & $\begin{array}{c}\text { Sensors } \\
\text { distance } \\
(\mathrm{m})\end{array}$ & $\begin{array}{c}\text { Angle } \\
(\mathrm{deg})\end{array}$ \\
\hline 0005 & HKD080 & - & 43.50786 & 144.44901 & 604 & 44 & 100.9 \\
0041 & FKS011 & - & 37.09071 & 140.90252 & 186 & 97 & -50.3 \\
0115 & HKD066 & - & 43.66182 & 145.13143 & 639 & 59 & 100.6 \\
0122 & HKD083 & - & 43.23294 & 144.32503 & 572 & 19 & 101.5 \\
0140 & HKD151 & - & 42.49436 & 140.35420 & 496 & 24 & 76.6 \\
0144 & HKD110 & - & 42.13094 & 142.93539 & 428 & 38 & 104.6 \\
0164 & IWT019 & - & 39.84918 & 141.80385 & 179 & 39 & 57.2 \\
0183 & AKT006 & - & 40.21544 & 140.78733 & 253 & 26 & 62.5 \\
0519 & HKD072 & - & 43.19517 & 145.52050 & 605 & 52 & 101.5 \\
0535 & AOM027 & - & 41.14555 & 140.82198 & 343 & 28 & 70.6 \\
0792 & HKD131 & - & 42.42055 & 141.08106 & 471 & 67 & 76.4 \\
0793 & - & TKCH08 & 42.48641 & 143.15197 & 470 & 10 & 103.24 \\
0864 & HKD065 & - & 43.79403 & 145.05686 & 650 & 38 & 100.3 \\
0877 & - & IKRH02 & 43.22090 & 141.65202 & 550 & 60 & 78.5 \\
0983 & - & NGNH28 & 36.70665 & 138.09673 & 416 & 98 & -57.8 \\
0991 & - & GIFH23 & 35.72349 & 136.78462 & 572 & 7 & -68.7 \\
0998 & - & AICH21 & 34.74005 & 136.93848 & 625 & 6 & -74.3 \\
0550 & MYG011 & - & 38.30119 & 141.50069 & 75 & 131 & 0.3 \\
0172 & MYG001 & - & 38.90286 & 141.57259 & 96 & 116 & 31.2 \\
0591 & GNM004 & - & 36.61632 & 138.59145 & 382 & 89 & -59.3 \\
0613 & - & NGNH19 & 35.97415 & 138.58303 & 423 & 129 & -66.7 \\
0945 & FKS015 & - & 37.02358 & 140.37627 & 225 & 123 & -51.8 \\
3088 & - & SZOH31 & 34.93980 & 138.07486 & 534 & 147 & 73.42 \\
\hline
\end{tabular}




\section{Methodology}

\subsection{Coherence analysis}

The coherence analysis is a broadly used technique for the cross-spectral density of two dataset in the frequency domain (Kim and Stewart, 2003; Mikami and Stewart, 2008; Moschas and Stiros, 2011) and it was used to assess the consistency of collocated GPS and strong-motion sites. The magnitude squared coherence was used, which is based on Welch's average modified periodogram, provided by Matlab. The magnitude squared coherence ranges between 0 and 1, considering that for coherence greater than 0.8 the two time series can be assumed strongly correlated in the frequency domain, while deviating coherence below 0.8 indicates significant noise spectrum (Kim and Stewart, 2003).

The coherence analysis for the common frequency range $(0-0.5 \mathrm{~Hz})$ of the $1 \mathrm{~Hz}$ GPS and $100 \mathrm{~Hz}$ strong-motion records was applied. However, before comparison, strong-motion data were decimated from 100 to $1 \mathrm{~Hz}$ resulting to compatible GPS and strong-motion records of $1 \mathrm{~Hz}$ sampling-rate and $300 \mathrm{sec}$ duration (time series of 300 samples). The opposite technique of upsampling GPS data using interpolation, etc. was not preferred, as i) the generated data would be subjected to potential correlated noise (Boore, 2005) and ii) down-sampling to $1-2 \mathrm{~Hz}$ is rather more usual technique for seismic records (Emore et al., 2007) and for source inversion, etc., due to the limitation of the velocity models (Houlie et al., 2014). Regarding the coherence analysis, it was used Hamming window of 100 samples, with overlapping of 90 seconds in order to cover broad range of frequencies (i.e. $0.005-0.5 \mathrm{~Hz}$ ).

\subsection{Displacement waveforms comparison}

The frequency bands for the assessment of the GPS and strong motion displacement time series were formed, based on an octave-wide distribution (Clinton and Heaton, 2003, Cauzzi and Clinton, 2013), the limitations of the sampling rate and the duration of the records. Specifically, the upper frequency limit was defined $0.4 \mathrm{~Hz}$, smaller than the Nyquist frequency and not close to the relative high frequency (i.e. $0.5 \mathrm{~Hz}$ ), where the GPS noise level is expected to be increased. Following the octave-wide distribution and having the $0.4 \mathrm{~Hz}$ as upper limit, there were formed 6 frequency bands for the assessment: i) $0.2-0.4 \mathrm{~Hz}$, ii) $0.1-0.2 \mathrm{~Hz}$, iii) $0.05-0.1 \mathrm{~Hz}$, iv) $0.025-0.05 \mathrm{~Hz}$, v) $0.0125-0.025 \mathrm{~Hz}$, and vi) $0.0061-0.0125 \mathrm{~Hz}$. The lowest frequency limit was $0.0061 \mathrm{~Hz}$, in order to avoid the low-frequencies $(<0.005 \mathrm{~Hz})$ of the displacement time series of the strong-motion sensors, which would suffer strongly by drifting (Wang et al., 2003), especially in the case of the examined strong-motion records due to their large record duration (e.g. $300 \mathrm{sec}$ ).

The second step was the band-pass filtering, which was done by using Chebyshev filter of $8^{\text {th }}$ order, which have more abrupt cut-off frequency than Butterworth filter (Boore and Bommer, 2005), without distorting significantly the data (Moschas and Stiros, 2013). The filter was applied twice, in forward and reverse direction, in order to limit potential phase shift of the derived time series. The strong-motion and the GPS displacement time series were filtered for each one of the examined frequency bands, resulting to six new displacement time series of GPS and strongmotion for every component of each collocated site. The application of the band-pass filtering to 
the strong-motion displacement time series for the examined frequency bands led to the limitation of the low-frequency drifting effect.

The next step was the cross-correlation analysis of the corresponding GPS and strong-motion displacement time series of each component (NS.EW,UP) and each frequency band of the collocated sites, for the detection of possible time lags. The latter can be due to the distance between the GPS and strong-motion sites or even clock drift of the strong-motion sensor, which cannot be regularly corrected (Moschas and Stiros, 2012).

Finally, based on the estimated time lag for each collocated displacement time series, the corresponding time series were shifted and compared by computing their relative difference, known as residuals. The obtained residuals were assessed by computing the corresponding standard deviation and their maximum value.

\section{Results}

\subsection{Coherence Analysis}

Fig. 2 shows the plots of coherence of four representative collocated sites, covering the distance range of 75-650km from the epicenter. The collocated sites (GPS:550 with K-NET:MYG011), which are close $(<200 \mathrm{~km})$ to the epicentre, appears high coherence $(>0.8)$ on the vertical component for the frequency range of $0.05-0.25 \mathrm{~Hz}$, whereas the corresponding frequency range of high coherence (i.e. $>0.8)$ for the horizontal components is rather limited $(0.05-0.1 \mathrm{~Hz})$. For collocated sites of moderate distance from the epicentre (i.e. $350 \mathrm{~km}$; GPS: 183 with KNET:AKT006), high coherence is observed both in horizontal and vertical components for frequencies ranging between $\sim 0.025$ and $0.3 \mathrm{~Hz}$, while far from the epicentre (i.e. $640 \mathrm{~km}$; GPS 115 with K-NET:HKD066), the range frequencies of high coherence of the horizontal components remains the same $(\sim 0.025-0.3 \mathrm{~Hz})$ and that of the vertical component is limited significantly $(0.03-$ $0.1 \mathrm{~Hz}$ ). Further analysis of the coherence was made based on the angle of each site, which is formed by the epicentre-site direction relatively to the west (Table 1). The coherence analysis does not show clearly a direct connection between the epicentre-site direction and the two horizontal components. The later might be due to the complexity of the seismic signal, which is caused by the large rupture surface and the two potential location of rupture (Suzuki et al., 2011; Koketsu et al., 2011).

However, the coherence analysis of the GPS and strong-motion data of the collocated sites shows strong evidence that the frequency range of high coherence $(>0.8)$ depends on the component (horizontal or vertical) and the distance of the site from the earthquake epicentre. This indicates that the consistency of the GPS and strong-motion records of the collocated sites, is relative with the directivity of the propagation of the seismic waves.

\subsection{Displacement waveforms comparison}

The displacement waveform analysis was applied for each one of the frequency bands and for each component of the 23 collocated GPS and strong-motion sites. Initially, the time lags between the GPS and strong-motion corresponding displacement time series were estimated, ranging between -2 and 3 seconds. The plot of the time lags of the three components of all frequency bands versus the distance from the epicentre shows that the time lags are independent of the distance 


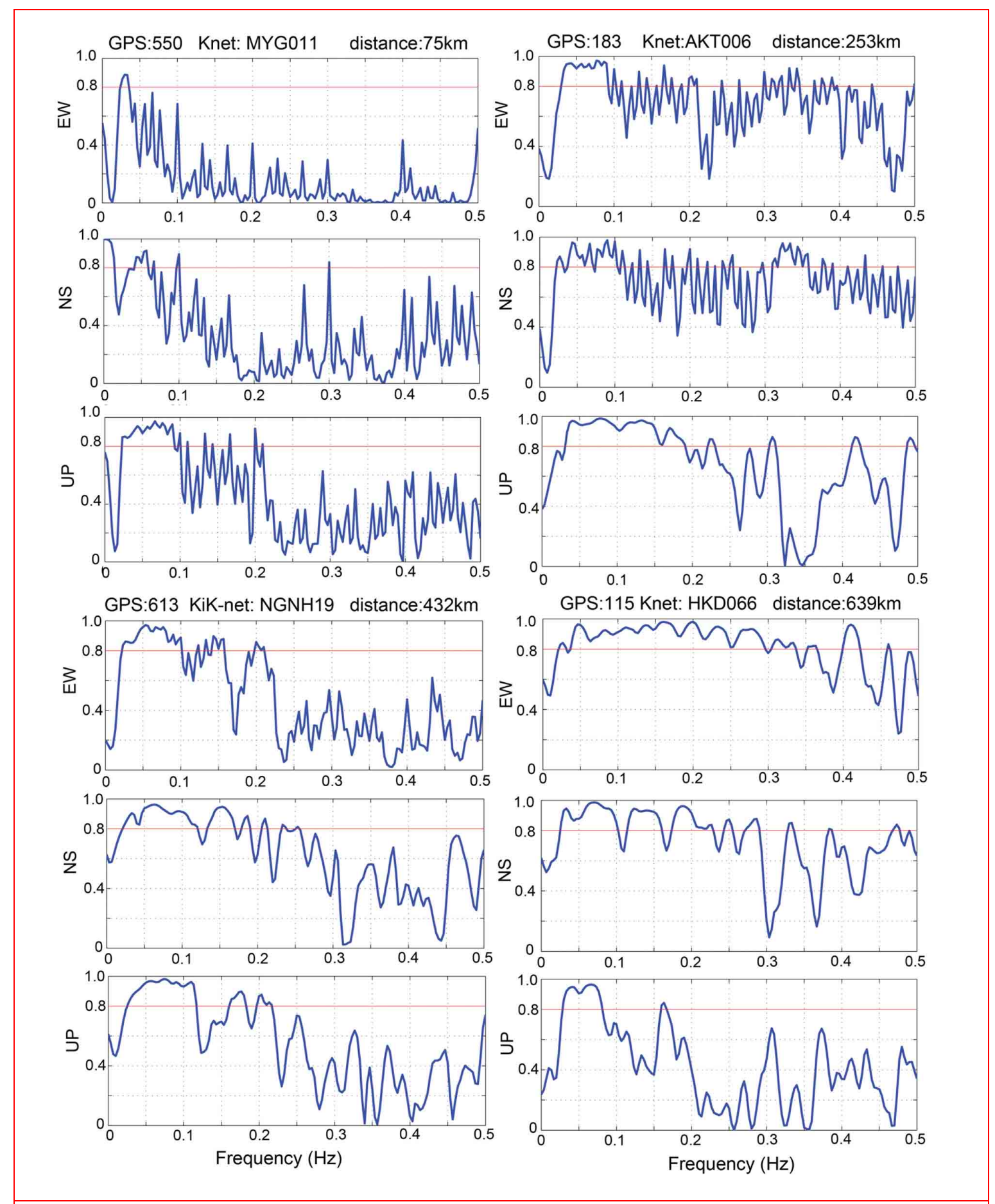

Fig. 2 Plots of the coherence analysis of four representative GPS and strong-motion collocated sites with distance from the epicentre from 75 to $640 \mathrm{~km}$. The horizontal line indicates the limit of 0.8 for the assessment of coherence. 


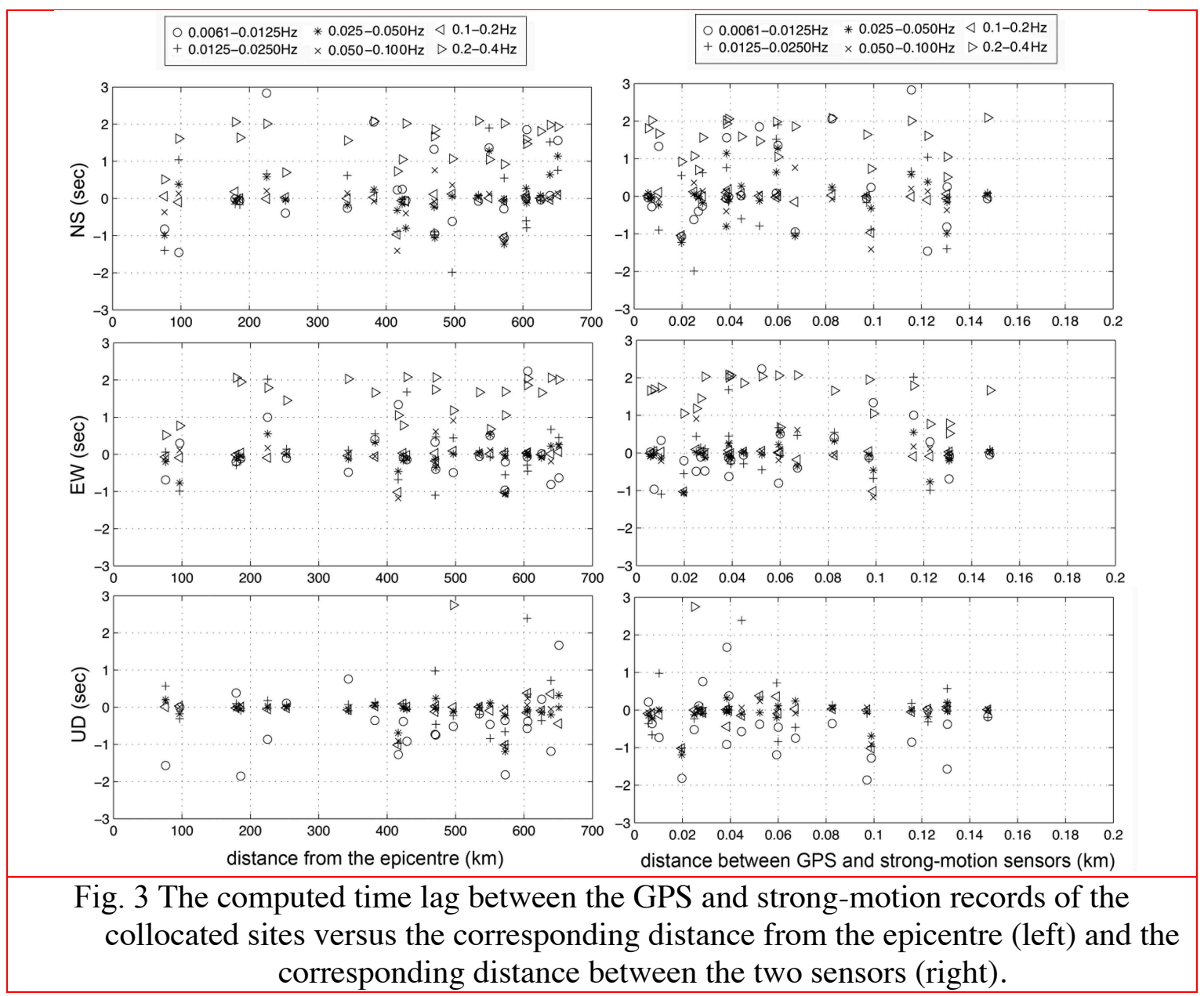

from the epicentre and less dispersion appears at the time lags of the vertical component relatively to that of the horizontal components (Fig. 3left). The larger time lag for each collocated site appears generally at the highest frequency band for the horizontal components, while for the upward component this appears at the lowest frequency band. Furthermore, the time lags seem to be independent of the distance between the collocated sensors (Fig. 3right), indicating that the latter did not affect the collocation conditions of the two sensors.

Based on the computed time lags of the collocated sites, the corresponding displacement time series were shifted for the "synchronisation" and the corresponding residuals were computed. In Fig. 4 are plotted the representative GPS and strong-motion displacement time series of the EW component and the corresponding residuals derived from the filtering for two frequency bands $(0.0061-0.0125 \mathrm{~Hz}$ and $0.225-0.5 \mathrm{~Hz})$, for three collocated sites (i.e. GPS:550 with KNET:MYG011, GPS:164 with K-NET: IWT019 and GPS:613 with KiK-net:NGNH19). The first impression of the GPS and strong-motion displacement time series reveal rather small relative amplitude difference (i.e. $\sim 6-7 \mathrm{~cm}$ for the GPS550 and K-NET MYG011), which finally proved to be significantly larger according to the corresponding computed residuals. The amplitude of the residuals decreases with 
the increase of the frequency band and the distance from the epicentre. This is made clearer by computing the standard deviation (Fig. 5) and the maximum value of the residuals (Fig. 6left). The standard deviations range mainly between a few sub-millimeters up to $10 \mathrm{~cm}$, while the maximum estimated residuals range between $1 \mathrm{~mm}$ and $30 \mathrm{~cm}$. By excluding the collocated sites very close to the epicentre $(<100 \mathrm{~km})$, the computed standard deviation and maximum residuals ranges are limited up to $4-5 \mathrm{~cm}$.

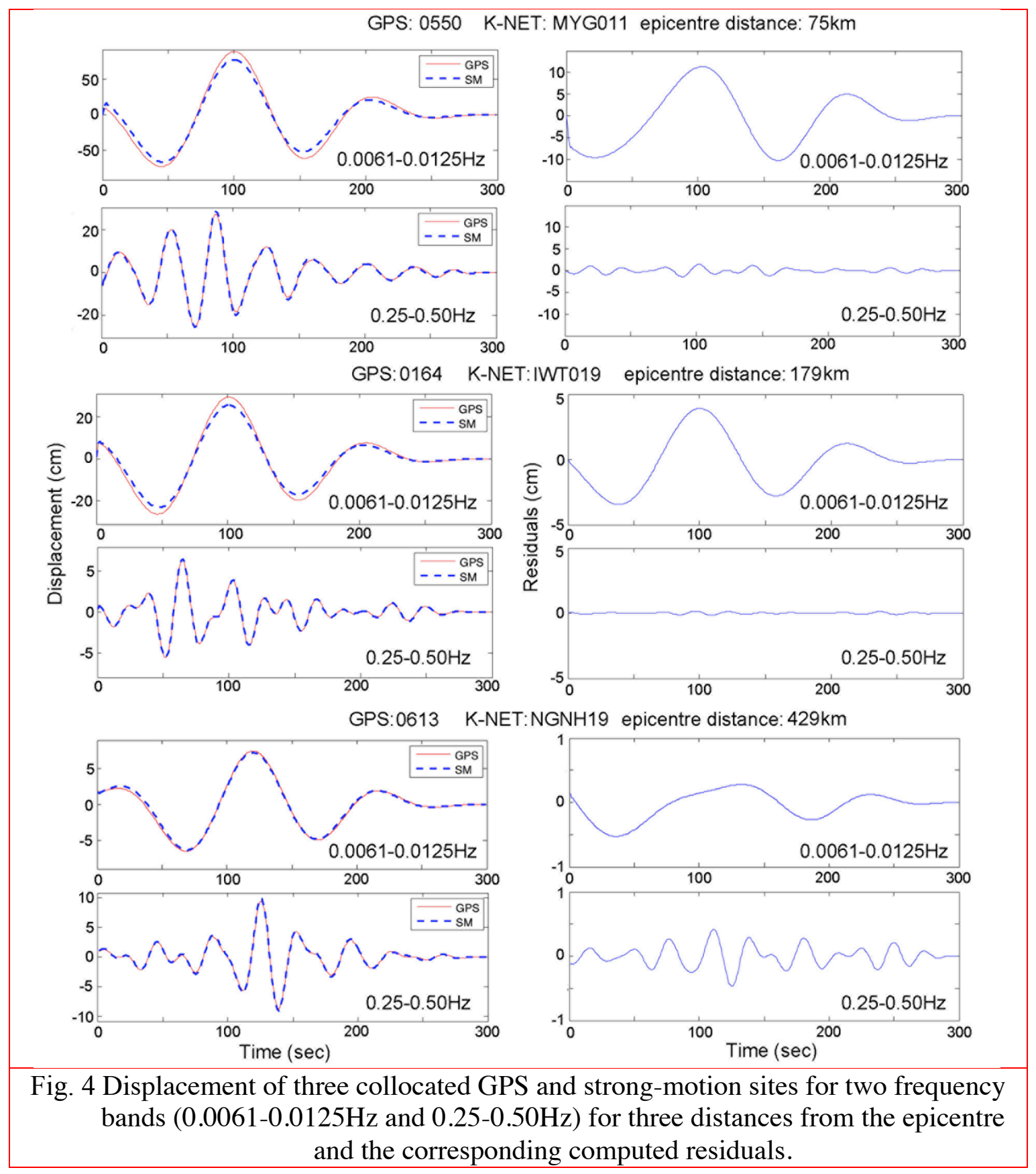




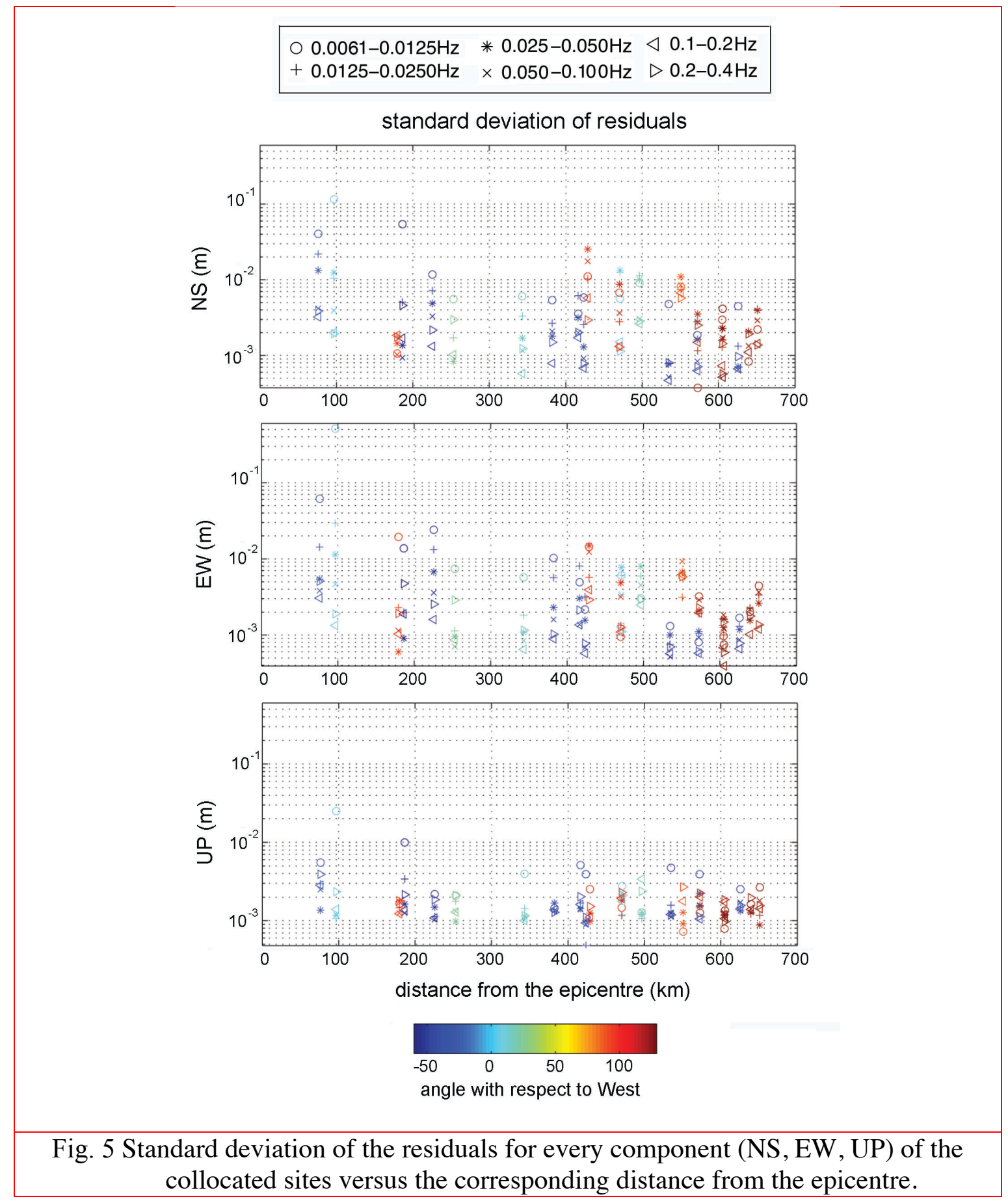

In both plots there is a general pattern of decrease of the standard deviation and the maximum residuals with the distance from the epicentre, mainly for the first $300-400 \mathrm{~km}$. For distance larger 
than $400 \mathrm{~km}$ the residuals seem to be more constant, below $1-2 \mathrm{~cm}$, with only exception the site of GPS:0144 with K-NET:HKD0110. Furthermore, the computed values of the upward component are smaller than these of the horizontal, mainly for distance close to the epicentre (i.e. $<100$ $150 \mathrm{~km})$.

Additionally, the largest maximum residuals and standard deviations correspond to the lowest frequency band for distance smaller than $400 \mathrm{~km}$ from the epicentre. For large epicentre distance $(>400 \mathrm{~km})$ the distribution of the frequency bands in the range of the estimated standard deviation and maximum residuals seems rather random.

However, the normalised maximum residuals, based on the maximum GPS displacement of the corresponding component, are generally increasing with the distance from the epicentre, ranging

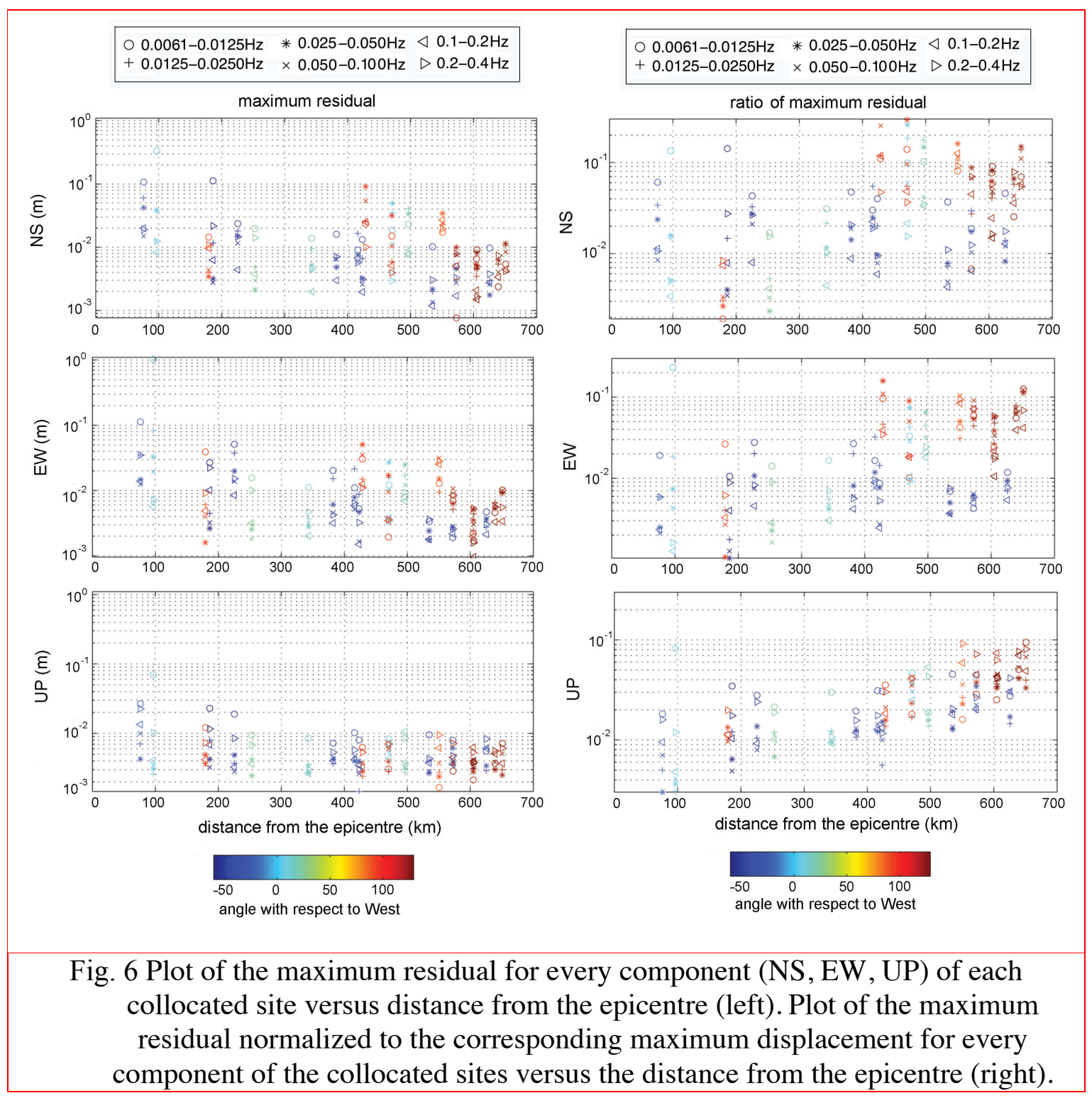


between 0.002 to 0.25 (Fig. 6right) and this is mainly due to the attenuation of the seismic signal. However, still the largest normalised residual is observed for the lowest frequency band for the distances less than $400 \mathrm{~km}$ from the epicentre, while for sites far from the epicentre $(>500 \mathrm{~km})$, the correspondence is rather random.

The residuals were further analysed, using the Discrete Fourier Transform (DFT), which generally reflected the distribution of the frequency bands in the range of the computed standard deviations. In Fig. 7 are presented the spectra of residuals of the six frequency bands for two representative collocated sites (GPS:613 with KiK-net:NGNH19 and GPS:164 with K-NET:IWT019), where the frequency bands greater then $>0.05 \mathrm{~Hz}$ reveal weak signals (of magnitude of sub-mm) with quite random frequency peaks expressing mainly noise of the measurements or even caused by possible data distortion from the band-pass filtering. For the frequency bands smaller than $0.05 \mathrm{~Hz}$, the revealed frequency peaks become more dominant especially for the sites relatively close to the epicentre (i.e. spectrum of EW of GPS:164 K-NET:ITW019 of frequency band of 0.0061-0.0125), appearing also consistency in some cases between the components of the site (i.e. EW-NS consistency of the detected frequencies for site GPS:613 K-NET:MYG001 for frequency band $0.0125-0.025 \mathrm{~Hz})$.

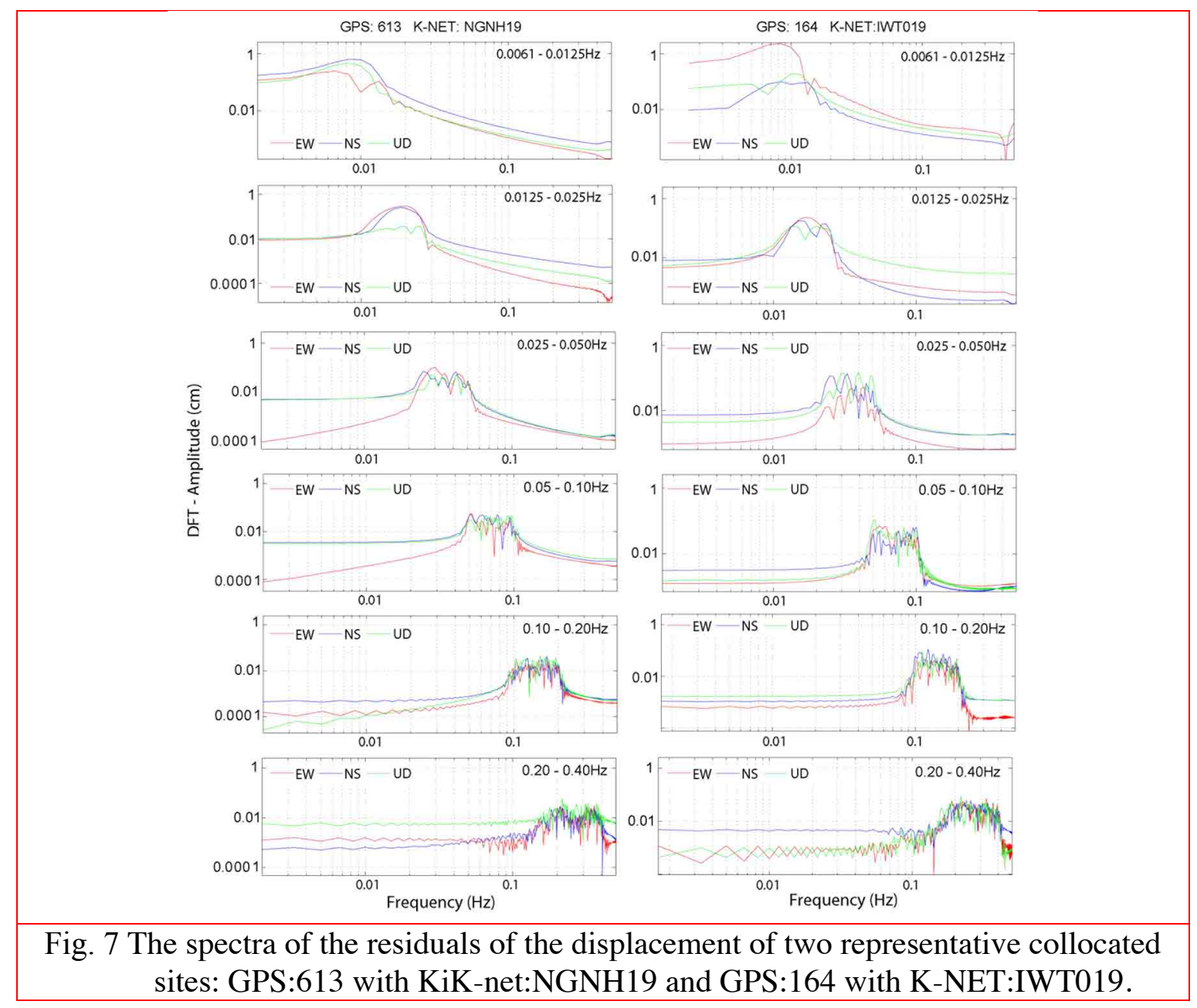




\section{Discussion}

The assessment of the consistency of GPS and strong-motion records using the coherence analysis in the frequency domain and the displacement comparison in the time domain for several frequency bands showed that the consistency of GPS and strong-motion sensors depends on the distance from the epicentre. For sites close to the epicentre $(<100-200 \mathrm{~km})$, higher consistency of GPS and strong-motion sensors appears more often on the vertical than the horizontal components, which reverses away from the epicentre (i.e. consistency for horizontals better than vertical component). Again, the reliability of the vertical components of motions appears to be better than the horizontal ones, likely because of the anisotropic distribution of GPS satellites in the sky (Houlié et al., 2011). The correlation of the seismic waves directivity with the consistency of the GPS and strong-motion networks is difficult due to the complexity of the rupture and the two potential sources (Suzuki et al., 2011; Koketsu et al., 2011). However, it is indicative that the EW direction appears smaller residuals than the NS direction. The latter expresses probably the better consistency of the collocated records in EW direction, which was the main direction of the propagation of the main seismic waves (Koketsu et al., 2011), than the NS direction.

Furthermore, the coherence analysis showed that for a frequency range of $0.025-0.1 \mathrm{~Hz}$, a high coherence $(>0.8)$ is estimated between the two signals whatever the component or the epicentre distances, indicating a frequency range of the best-expected consistent GPS and strong-motion records.

The large maximum residuals (i.e. up to $10 \mathrm{~cm}$ for GPS0550 with K-NET MYG011) of the relatively close distant $(<400 \mathrm{~km})$ collocated sites corresponding to band of $0.0061-0.0125 \mathrm{~Hz}$ can be attributed mainly to the phase shift between the GPS and strong-motion time series. The phase shift is not constant and it is probably due to random phase delays of the accelerometer, independently from the motion characteristics (Moschas and Stiros, 2012). This effect decreases with the increase of the frequency, due to the weak displacement signal of this frequency band.

However, for collocated sites located far from the epicentre, weak displacement signal in combination with GPS noise level may lead to poor correlation between the two families of signals, suggesting that GPS is not the best tool to use to constrain displacement where the displacement is close to the formal error of PPP processing. Furthermore the weaker propagated seismic signal northern from the epicentre (Koketsu et al., 2011) also contributed to the generally relative larger residuals at the sites northern from the epicentre than those southern from the epicentre. This is another indication of the correlation between the direction of the seismic signals and the consistency of the GPS and strong-motion records.

Furthermore, direct evaluation of which of the two strong-motion network (K-NET and KiKNET) is more consistent with that from GPS is rather difficult, due to the relative small number of site-samples (16 K-NET and $7 \mathrm{KiK}$-net). However, there seems a slightly better consistency between GPS and KiK-NET network, based on the maximum residuals (Fig. 7) of the indicative sites of GPS:0991/KiK-NET: GIFH13 and GPS:0122/K-NET:HKD083 (Table 1), which are approximately in the same distance from the epicentre. The latter might the result of the better foundation of KiK-NET on a rock or thin layer of sediment (Wang et al., 2013).

Potential local effects might contribute on the sites residuals. However, this contribution is expected to be rather small due to the strict collocation criterion of $100 \mathrm{~m}$ sensors distance, which 
is rather conservative relatively to other studies (Wang et al., 2013), and should not affect the general trend of the estimated residuals for the examined sites.

To summarize, the ratio of the residuals of GPS and strong-motion displacement difference to the maximum corresponding GPS displacements, for all the frequency bands, increase with the distance from the epicentre, which is due to the attenuation of the seismic signal (Fig. 2), resulting to deviation corresponding up to $20 \%$ of the maximum corresponding displacement far from the epicentre ( $>400 \mathrm{~km})$. The high ratio of the residuals to maximum GPS displacement (up to $10 \%$ )for the sites (i.e. GPS550 with K-NET MYG011 and GPS179 with K-NET MYG001) very close to the epicentre $(<100 \mathrm{~km})$ correspond to the NS component and apart from the phase shift it may also be attributed to tilting of the strong-motion sensor contributing wrongly to the recording of the NS component. Generally, the GPS and the strong-motion displacement waveforms can calibrate and correct the one the other, by using the GPS for the low frequencies $(<0.01 \mathrm{~Hz})$ and permanent displacement and the strong-motion for the relative high-frequencies $(>0.3-0.4 \mathrm{~Hz})$, considering also the component and the relative location from the epicentre.

\section{Implications for Structural Health Monitoring and Earthquake Engineering}

Previous studies have shown the significance of the displacement waveforms for the design of the structure (Panagiotakos and Fardis, 1999; Adhikari et al., 2010; Penucci et al,. 2009; Sadan et al., 2013) and revealed the need of using geodetic techniques and especially GNSS technology. The combined use of GNSS and strong-motion sensors (accelerometers/seismometers) is not only for covering the drawback of the strong-motion sensors in the very low-frequencies $(<0.01 \mathrm{~Hz}$; Wang et al., 2003). The consistency of GPS and strong-motion sensors in specific frequency range of motion gives the potential to overcome their malfunctions (e.g. rotation of the strong-motion sensors, errors in GPS measurement due to poor satellite constellation, etc.) and supplement each other. The supplementary use should aim mainly on the their mutual calibration and correction the one the other their errors, considering always their location relatively to the earthquake epicentre. The calibration technique is already applied successfully in geodetic measurements (Moschas et al., 2013) and it can lead to the creation of "combo" stations including both GNSS and strong-motion sensor for the structural health monitoring. Ultimately, the "combo" stations will be used for the correction of nearby GNSS or strong-motion sensors "single" stations (Psimoulis and Stiros, 2012). The aim will be the final estimation of the displacement response in full frequency range.

The combined use of GNSS and strong-motion sensors can contribute in the study of the soilstructure interaction during an earthquake by recording motions i) underground, below and around the structure foundations, ii) on the ground surface using it as reference level, iii) of indoor structures parts and iv) on top of structure, by using "combo" and "single" stations of GNSS and strong-motion sensors. For instance, for the case of monitoring of a tall building, "combo" GNSS and strong-motion stations will be set on the ground surface and on top of the structure. The "combo" stations will be used for the definition of the sensors consistency, for calibration of the one the other displacement amplitude and finally the estimation of the displacement of the corresponding monitoring points. The calibration of these GNSS and strong-motion records will be used for the corrections of the corresponding nearby GNSS/strong-motion "single" stations. The strong-motion "single" stations will be used as underground stations for soil motion and as intermediate floor indoor stations for the estimation of the displacement in the corresponding 
floors. The GNSS "single" stations can be used on the top of the building for the detection of potential rotations and tilts, which cannot be detected by the strong-motion sensors (Geng et al., 2014). The main advantage of this approach is the use of the consistency of the sensors for their calibration and correction and the estimation of the motion (3-D displacement and corresponding rotations) of the entire soil structure interaction system (from underground to top of the structure), limiting simultaneously the cost of the stations by using several "single" GNSS/strong-motion stations.

Apart from the structural health monitoring, significant contribution for the earthquake engineering would be the fast and reliable definition of displacement waveforms derived from combined after an earthquake. Furthermore, the comparison of the derived GNSS and strongmotion displacement waveforms, in combination with corresponding detailed geological maps may reveal local geological formations (basins, etc.), which amplify the seismic signal and will be valuable for the design of the structures.

\section{Conclusions}

The consistency of GPS and strong-motion records was examined for the recording of the megathrust earthquake of Mw9.0 Tohoku 2011, an extreme case for seismic rupture. It was shown that the frequency range of the consistent application of the two monitoring systems and how that depends on the motion frequency and the location relative to the excitation source. Even under

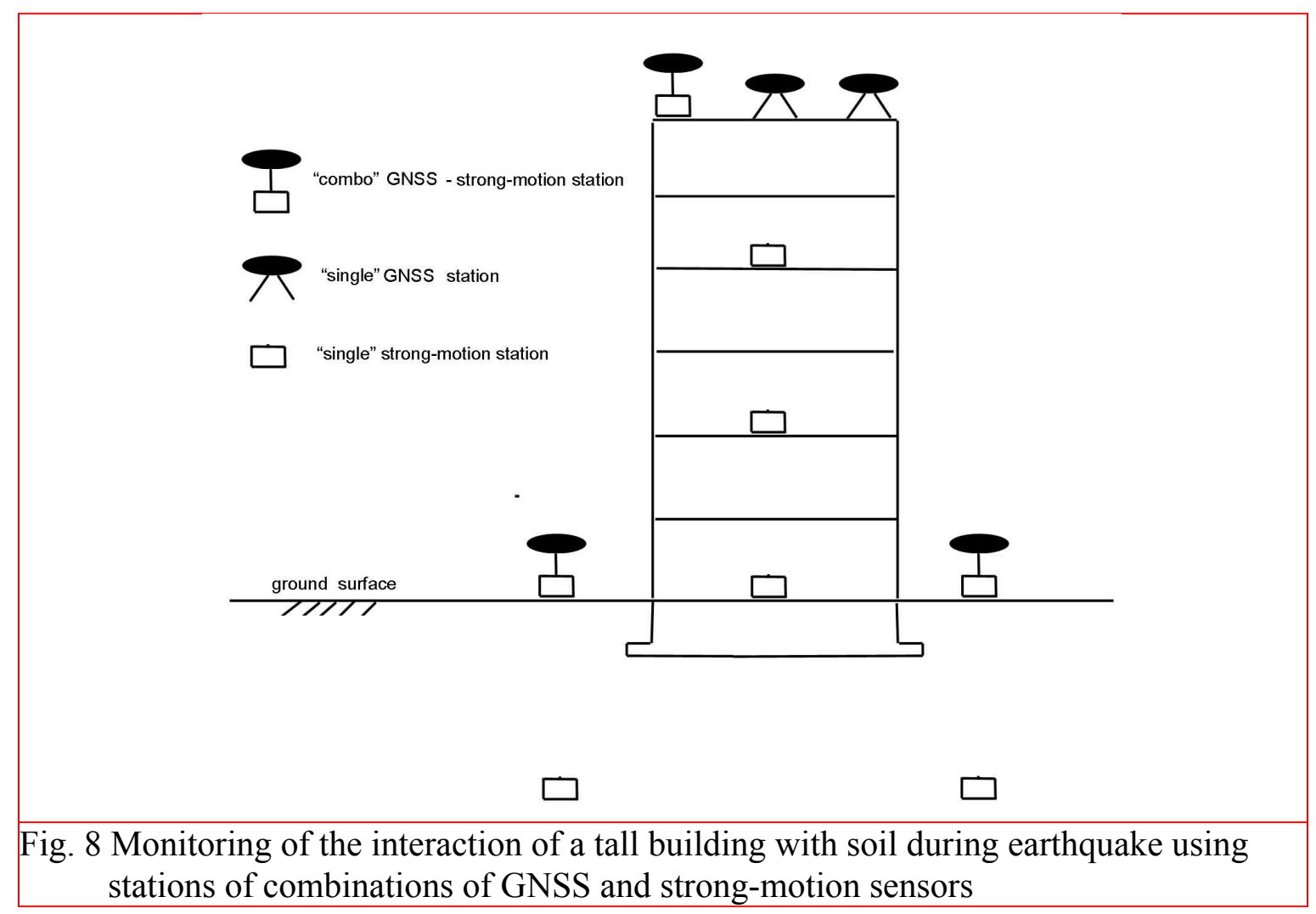


these extreme ground motion, the two systems can supplement and correct successfully each other by using i) GPS for very low frequency $(<0.01 \mathrm{~Hz})$ ii) combination of GPS and strongmotion/accelerometer for moderate frequencies $(>0.01 \mathrm{~Hz}$ and $<0.3 \mathrm{~Hz})$ and iii) strongmotion/accelerometer for high frequencies $(>0.3 \mathrm{~Hz})$, taken into consideration always the relative phase shift between the derived displacement of the two systems. Further study of GPS and strongmotion sensors records from additional seismic events and sites closer to the epicentre $(<75 \mathrm{~km})$ will define more accurately the consistency of the two sensors and their potential supplementary use.

The conclusions of this study show that GPS and strong-motion/accelerometers can be used jointly supplementing each other by correcting one the other, providing more efficient structural health monitoring. However, the proper modeling of the phase shift/delay of the two systems is still very important task and will improve the fusion and merge of the two records (Chatzi and Smyth, 2009) even in real-time (Geng et al., 2013), affecting finally the efficiency of the structural health monitoring and the earthquake engineering.

\section{Acknowledgements}

This study has been supported by Swiss National Fund grants in the framework of the "High-rate GNSS for Seismology" 200021_130061 project. The two anonymous reviewers are very thanked for their constructive comments.

\section{References}

Adhikari, G., Petrini, L., Calvi, G.M., (2010), “Application of direct displacement based design to long bridges”, Bull. Earthq. Eng., 8(4), 897-919

Aoi, S., Kunugi, T., Fujiwara, H., (2004), "Strong-motion seismograph network operated by NIED: K-NET and KiK-net”, J. Jap. Ass. Earthq. Eng., 4(3), 65-74.

Blewitt, G., Kreemer, C., Hammond, W.C., Plag, H.-P., Stein, S., Okal, E., (2006), "Rapid determination of Earthquake magnitude using GPS for Tsunami Warning Systems", Geophys. Res. Lett. 33, L11309.

Boore, D.M., (2003), "Analog-to-digital conversion as a source of drifts in displacements derived from digital recording of ground acceleration", Bull. Seism. Soc. Am. , 93(5), 2017-2024.

Boore, D.V., Bommer, J. J., (2005), "Processing of strong-motion accelerograms: needs, options and consequences", Soil Dyn. Earthq. Eng., 25(2), 93-115

Boore, D.M., (2005) "On pads and filters: Processing strong-motion records", Bull. Seism. Soc. Am., 95(2), 745-750.

Bock, Y., Prawirodirdjo, L., and Melbourne, T., (2004), "Detection of arbitrary large dynamic ground motions with a dense high-rate GPS network", Geophys. Res. Lett., 31, L06604.

Bock, Y., Melgar, D., Crowell, B., (2011), "Real-time strong-motion broadband displacements from collocated GPS and accelerometers", Bull. Seism. Soc. Am., 101(6), 2904-2925.

Cauzzi, C., Clinton, J., (2013), “A high- and low-noise model for high-quality strong-motion accelerometer stations", Earthq.Sp., 29(1), 85-102

Chan, W.S., Xu, Y.L., Ding, X.L., Dai, W.J., (2006), “An integrated GPS-accelerometer data processing technique for structural deformation monitoring", J. Geod., 80(12), 705-719 
Chatzi, E.N., Smyth, A.W. (2009), "The unscented Kalman filter and particle filter methods for nonlinear structural system identification with non-collocated heterogeneous sensing", Str. Contr. Heal. Mon., 16, 99-123

Chatzi, E.N., Fuggini, C., (2012), "Structural identification of a super-tall tower by GPS and accelerometer data fusion using a multi-rate Kalman filter", Life-cycle and Sustainability of Civil Infrastructure Systems - Proc. of $3^{\text {rd }}$ Int. Symp. on Life-Cycle Civil Engineering, IALCCE, 2012, 144-151

Chousianitis, K., Ganas, A., Gianniou, M., (2013), "Kinematic interpretation of present-day crustal deformation in central Greece from continuous GPS measurements", J. Geodyn., 71, 1-13

Clinton, J. F., Heaton, T.H., (2003), "Potential Advantages of a strong-motion velocity-meter over a strongmotion accelerometer", Seism. Res. Lett., 73(3), 332-342.

Crowell, B.W., Bock, Y., Squibb, M.B. (2009), "Earthquake early-warning using total displacement waveforms from real-time GPS networks", Seism. Res. Lett., 80(5), 772-782.

Dach, R., Hugentobler, U., Meindl, M., Fridez, P. (2007), “The Bernese GPS Software Version 5.0, Astronomical Institute", University of Bern, Switzerland.

Dach, R., Brockmann, E., Schaer, S., Beutler, G., Meindl, M., Prange, L., Bock, H., Jäggi, A., Ostini, L., (2009), “GNSS processing at CODE: status report”, J. Geod., 83(3-4), 353-366.

Emore, G.L., Haare, J.S., Choi, K., Larson, K.M., Yamagiwa, A., (2007), "Recovering seismic displacement through combined use of 1-Hz GPS and strong-motion accelerometers", Bull. Seism. Soc. Am., 97(2), 357-378

Feng, M.Q., (2009), “Application of structural health monitoring in civil infrastructure", Sm. Str. Sys., 5(4), 469-482.

Feng, L., Newman, A., Farmer, g., Psimoulis, P., Stiros, S. (2010), "Strong rupture, coseismic and postseismic response of the 2008 Mw 6.4 Patras Earthquake in Northwestern Pelopennese, Greece: An indicator for a new transform fault zone", Geoph. J. Int., 183(1), 103-110.

Ganas, A., Serpelloni, E., Drakatos, G., Kolligri, M., Adamis, I., Tsimis, C., Batsi, E., (2009), "The Mw6.4 SW-achaia (Western Greece) earthquake of 8 June 2008: Seismological, field, GPS observations, and stress modeling", J. Earthq. Eng., 13(8), 1101-1124

Ge, M., Gendt, G., Rothacher, M., Shi, C., Liu, J., (2008), "Resolution of GPS carrier-phase ambiguities in Precise Point Positioning (PPP) with daily observations", J. Geod., 82(7), 389-399.

Geng, J., Teferle, F.N., Meng, X., Dodson, A.H., (2011), “Towards PPP-RTK: Ambiquity resolution in real-time precise point positioning", Adv. Spac. Res., 47(10), 1664-1673.

Geng, J., Bock, Y., Melgar, D., Crowell, B.W., and aase, J.S., (2013), “A new seismogeodetic approach applied to GPS and accelerometer observations of the 2012 Brawley seismic swarn: Implications for earthquake early warning", Geoch. Geoph. Geosys., 14(7), 2124-2142

Geng, J., Melgar, D., Bock, Y., Pantoli, E., J., Restrepo, (2013), "Recovering coseismic point ground tilts from collocated high-rate GPS and accelerometers", Geoph. Res. Lett., 40(19), 50955100

Giri, P. Lee, J.-R., (2013), "In-situ blade deflection monitoring of a wind turbine using a wireless laser displacement sensor device within the tower", Key Eng. Mat., 558, 84-91.

Houlié, N., Occhipinti, G., Shapiro, N., Lognonné, P., and Murakami, M. (2011), "New approach to detect seismic surface waves in 1Hz-sampled GPS time series", Sci. Rep. 1(44).

Houlié, N., Dreger, D. \& Kim, A. (2014), "GPS source solution of the 2004 Parkfield earthquake", Sci. Rep. 4, 3646.

Joakinen, A., Feng, S., Schuster, W., Ochieng, W., Hide, C., Moore, T., Hill, C., (2013), "Integrity monitoring of fixed ambiguity Precise Point Positioning (PPP) solutions”, Geosp. Inf. Sc. 16(3), 141-148. 
Kim, S., Stewart, J.P., (2003), "Kinematic soil-structure interaction from strong-motion recordings", J. Geotech. Geoenv. Eng., 129, 323-335

Koketsu K, Yokota Y, Nishimura N, Yagi Y, Miyazaki S, Satake K, Fujii Y, Miyake H, Sakai S, Yamanaka Y, Okada T (2011) A unified source model for the 2011 Tohoku earthquake. Ear. Plan. Sc. Lett., 310: 480-487.

Kuyuk, H.S, Allen, R.M., (2014), "A threshold based earthquake early warning system: Quake Wave Vibration Report" Earthquake Early Warning System: Applications to the IberoMaghrebian Region, USA, 4-5 February 2014

Larson, K., Bodin, P., and Gomsberg, J. (2003), "Using 1-Hz GPS Data to Measure Deformations Caused by the Denali Fault Earthquake", Science 300, 1421-1424.

Mikami, A., Stewart, JP. (2008), "Effects of time series analysis protocols on transfer functions calculated from earthquake accelerograms", Soil Dyn. Earthq. Eng., 28, 695-706

Miyazaki, S., et al. (2004), "Modeling the rupture process of the 2003 September 25 Tokachi-Oki

(Hokkaido) earthquake using 1-Hz GPS data". Geophys. Res. Lett., 31, L21603.

Meng, X., Dodson, A.H., Roberts, G.W., (2007), "Detecting bridge dynamics with GPS and triaxial accelerometers", Eng. Str., 29, 3178-3184.

Meng, G., Ren, J., Su, X., Yang, Y., Zhu, Z., Ge, L., Li, X., (2013), “Coseismic Deformation of the

2010 Mw 6.9 Yushu Earthquake Derived from GPS Data”, Seis. Res. Lett., 84(1), 57-64

Moschas, F., Stiros, S., (2012), "Phase effect in time-stamped accelerometer measurements - An experimental approach", Int. J. Metr. Qual.Eng., 3 (3), 161-167.

Moschas, F., Stiros, S., (2013), "Noise characteristics of high-frequency, short-duration GPS records from analysis of identical, collocated instruments", Measur., 46, 1488-1506

Moschas, F., Stiros, S., (2014), "Three-dimensional dynamic deflections and natural frequencies of a stiff footbridge based on measurements of collocated sensors", Str. Con. Heal. Mon., 21(1), $23-42$

Moschas, F., Psimoulis, P., Stiros, S. (2013), "GPS-RTS data fusion to overcome signal deficiencies in certain bridge dynamic monitoring projects", Sm. Str. Sys., Special Issue: Intelligent Information Processing Technology in Structural Health Monitoring, 12 (3-4), 251269.

Moschas, F., Avallone, A., Saltogianni, V., Stiros, S. (2014), "Strong-motion displacement waveforms using 10Hz PPP-GPS: an assessment based on free-oscillation experiments", Earthq. Eng. Str. Dyn., (in press)

Panagiotakos, T.B., Fardis, M.N., (1999), "Deformation-controlled earthquake resistant design of

RC buildings", J. Earthq. Eng., 3(4), 495-518.

Penucci, D., Calvi, G.M., Sullivan, T.J., (2009), "Displacement-based design of precast walls with additional dampers", J. Earthq. Eng., 12(1), 109-131

Psimoulis, P., Stiros, S., (2013), "Measuring deflections of a short-span railway bridge using a Robotic Total Station (RTS)", J. Br.Eng., ASCE, 18(2), 182-185

Psimoulis, P., Stiros, S., (2012). "A supervised learning computer-based algorithm to derive the amplitude of oscillations of structures using noisy GPS and robotic theodolites (RTS) records", Comp. Str., 92-93, 337-348

Psimoulis, P. and Stiros, S. (2008), "Experimental assessment of the accuracy of GPS and RTS for the determination of the parameters of oscillation of major structures, Int. J. Comp.- Aid. Civ. Infr. Eng., 23, 389-403

Psimoulis, P., Pytharouli, S., Karambalis, D. and Stiros, S. (2008), "Potential of GPS to measure frequencies of oscillation of engineering structures", J. Soun. Vibr., 318, 606-623 
Roberts, G.W., Meng, X., Dodson, A.H., (2004), "Integrating a global positioning system and accelerometers to monitor deflection of bridges", J. Surv. Eng., 130(2), 65-72

Sadan, O.B., Petrini, L., Calvi, G.M., (2013), "Direct displacement-based seismic assessment procedure for multi-span reinforced concrete bridges with single column piers", Earthg. Eng. Str. Dyn., 42(7), 1031-1051

Sagiya, T., Kanamore, H., Yagi, Y., Yamada, M., Mori, J. (2011), "Rebuilding seismology", Nature, 473, 146-148.

Sagiya, T., (2004), “A decade of GEONET: 1994-2003 - The continuous GPS observation in Japan and its impact on earthquake studies", Ear. Pl. Spac., 56, xxix-xli

Stiros, S., (2008), "Errors in velocities and displacements deduced from accelerographs: An approach based on the theory of error propagation", Soil Dyn. Earthq. Eng., 28, 415-420.

Suzuki W, Aoi S, Sekiguchi H, Kunugi T (2011) Rupture process of the 2011 Tohoku-Oki megathrust earthquake (M9.0) inverted from strong-motion data. Geoph. Res. Let., 38: L00G16.

Wang, G., Boore, D. M., Tang, G., and Zhou, X. (2007), "Comparisons of ground motions from collocated and closely spaced one-sample-per-second Global Positioning System and accelerograph recordings of the 2003 M6.5 San Simeon, California, earthquake in the Parkfield Region", Bull. Seismol. Soc. Am., 97(1B), 76-90.

Wang G.Q., Boore D.M., Igel H., Zhou X.Y. (2003), "Some observations on collocated and closely spaced strong ground-motion records of the 1999 Chi-Chi, Taiwan, earthquake", Bull. Seism. Soc. Am., 93(2): 674-93.

Wang, K., Rothacher, M., (2013), "Ambiguity resolution for triple-frequency geometry-free and ionosphere-free combination tested with real data", J. Geod., 87(6), 539-553.

Wang, R., Parolai, S., Ge, M., Jin, M., Walter, T.R., Zschau, J., (2013), "The 2011 M $_{w} 9.0$ Tohoku earthquake: Comparison of GPS and strong-motion data”, Bull. Seism. Soc. Am., 103(2b),

Wright, T., Houlié, N., Hildyard, M., Iwabuchi, T., (2012), "Real-time, reliable magnitude for large earthquakes from $1 \mathrm{~Hz}$ GPS precise point positioning: The 2011 Tohoku-Oki (Japan) earthquake", Geoph. Res. Let., 39, L12302.

Xu, P., Shi, C., Fang, R., Liu, J., Niu, X., Zhang, Q., Yanagidani, T., (2013), "High-rate precise point positioning (PPP) to measure seismic wave motions: an experimental comparison of GPS PPP with inertial measurement units

Yi, T.-H., Li, H.-N., Gu, M., (2013), "Experimental assessment of high-rate GPS receivers for deformation monitoring of bridge", Measur., 46(1), 420-432.

Yue, H., Lay, T., (2011), "Inversion of high-rate (1sps) GPS data for rupture process of the 11 March 2011

Tohoku earthquake $\left(\mathrm{M}_{\mathrm{w}} 9.1\right)$ ”, Geoph. Res. Let., 38, L00G09. 